Article

\title{
Something's Got to Give: Reconsidering the Justification for a Gender Divide in Sport
}

\author{
Andria Bianchi 1,2 \\ 1 Department of Bioethics, University Health Network, Toronto, ON M5G 2A2, Canada; \\ andria.bianchi@uhn.ca; Tel.: +1-416-333-6677 \\ 2 Department of Philosophy, University of Waterloo, Waterloo, ON N2L 3G1, Canada
}

Received: 19 April 2019; Accepted: 12 May 2019; Published: 15 May 2019

\begin{abstract}
The question of whether transgender athletes should be permitted to compete in accordance with their gender identity is an evolving debate. Most competitive sports have male and female categories. One of the primary challenges with this categorization system, however, is that some transgender athletes (and especially transgender women) may be prevented from competing in accordance with their gender identity. The reason for this restriction is because of the idea that transgender women have an unfair advantage over their cisgender counterparts; this is seen as a problem since sports are typically guided a principle called 'the skill thesis', which suggests that sports are supposed to determine who is most skillful by maintaining a fair starting point. In this paper, I argue that if the skill thesis ought to be maintained and there continues to exist no conclusive evidence in support of unfair advantages possessed by trans women, then we may want to re-consider the gender binary in sport. Rather than having male/female categories, it may make more sense to categorize athletes based other sport-specific factors (e.g., height, weight, etc.). This may help to maintain the skill thesis while at the same time removing potentially unfair and discriminatory barriers against transgender athletes.
\end{abstract}

Keywords: transgender; trans women; sport; testosterone; gender; gender binary

\section{Introduction}

Mainstream discussions centred on trans-inclusivity have become ubiquitous. This increase has influenced some common social practices to change, such as having gender neutral washroom facilities and developing gender neutral dance studios (where traditional male/female roles are non-existent) [1,2]. The sports world, however, continues to grapple with challenges and controversies involving transgender people. The male/female gender binary continues to exist in most sporting events, and the idea that transgender women may possess unfair advantages is a widespread belief.

In 2017, I responded to the claim that transgender women possess unfair advantages when competing in female categories because of high testosterone levels [3]. The argument against trans women competing in female categories is motivated by the idea that a person's success in sports should be based solely on skill and not on unequal advantages or starting points between competitors; this is referred to as the skill thesis. In response, I suggested that genetic advantages already exist in sports, making it such that a fair and equal starting point is impossible to achieve. I ultimately suggested, however, that if maintaining the skill thesis and mitigating unfair advantages is important, then both transgender and cisgender athletes should be subjected to a handicap system.

There continues to be significant ethical debate regarding how to manage transgender women in sport; minimal headway has been made since 2017. In response to the ongoing debate, this article expands on my previous argument by considering the importance and suitability of the male/female gender binary. While recognizing that the skill thesis may not be seen as entirely foundational for 
everyone, I suggest that if we want to maintain the skill thesis as a guiding principle in sport (since it is currently, indeed, a guiding principle), then we need to reconsider whether it makes sense to categorize athletes based on their sex assignment at all. Perhaps it may be more sensible to categorize athletes based on other potentially relevant factors, such as height, weight, testosterone levels (if it is found that testosterone levels are, in fact, relevant), etc. In the first section of this paper, I offer a brief description of what it means to be transgender. I subsequently give an overview of some of the primary cases and controversies involving transgender women competing in female categories. The third section of this paper describes my previous proposal to implement a handicap system for both transgender and cisgender athletes. Finally, I expand on this proposal and ultimately suggest that it may be time to reconsider the gender binary in sports; this proposal also serves as a different, yet relevant expansion of Torbjörn Tännsjö's argument and Melanie Newbould's proposal to eliminate sex specific categories $[4,5]$. Reconsidering the gender binary may be a worthwhile pursuit in order to: (1) maintain the skill thesis and (2) establish an inclusive and equally competitive environment for all athletes. An alternative approach may be to simply abandon the skill thesis and allow transgender women to compete in female categories. Because the skill thesis is so pervasive, however, this paper considers strategies that maintain it as a guiding principle.

\section{What Does it Mean to be Transgender?}

The term 'transgender' or 'trans' is used to describe people "with diverse gender identities and gender expressions that do not conform to stereotypical ideas about what it means to be a girl/woman or boy/man in society [6]." A transgender person identifies with a gender that differs from their sex, where a person's sex is usually assigned at birth and based on factors such as hormones and reproductive systems. It is typically assumed that a person who is transgender is either a trans man (i.e., a person whose sex assignment is female and gender identity is male) or a trans woman. However, the term can more broadly refer to a person who "identif[ies] themselves as having no gender, a mix of both genders, or a gender that changes over time [7]." The term 'cisgender' or 'cis' describes people whose gender identity accords with their sex assignment (e.g., a person with a female sex assignment who identifies as a woman).

According to the National Center for Transgender Equality in the United States, a person of any age may realize they are transgender [8]. Some people know that they are trans from a young age. Others may spend much of their life feeling as though they do not fit in and/or do not accord with expectations and assumptions regarding their gender but are unable to name the reason. However, "[a]s transgender people become more visible in the media and in community life ... more transgender people are able to name and understand their own experiences and may feel safer and more comfortable sharing it with others [8]." This may be, at least in part, the reason that an increasing number of people have been openly identifying as trans over the last few years [9-11].

Although more people are identifying as transgender, normative assumptions regarding the male/female gender binary continue to exist (e.g., ideas about what a person's sexual anatomy should be, appropriate pronoun usages, etc.). Consequently, people whose gender identities extend beyond and/or differ from normative conceptions are often judged, marginalized, and shunned from the normalcy that cisgender people are granted in society (more specifically, cisgender people whose gender expression ${ }^{1}$ accords with normative expectations) [12]. There are many examples of some of the challenges that transgender people encounter on a regular basis. One of these examples is that of employment, where occurrences such as the "refusal to hire, privacy violations, harassment, and even physical and sexual violence on the job" are prevalent amongst the trans population [13]. A high risk of suicidality is another consequence that sometimes stems from the discrimination and stigma that trans people face [14]; the TransPulse Survey (a survey that considered the health needs

1 The term 'gender expression' is the way that a person expresses their gender identity. 
of transgender people in the province of Ontario, Canada) found that $77 \%$ of survey respondents seriously contemplated and $45 \%$ attempted suicide [15]. Moreover, a 2017 poll found that "[r]oughly one in six LGBTQ ${ }^{2}$ people say they have avoided medical care $(18 \%)$ and calling the police $(15 \%)$, even when in need, due to concern that they would be discriminated against because of their LGBTQ identity [16,17]."

As a result of these challenges and possible consequences, there are a growing number of support services available for transgender citizens and new human rights policies that aim to protect them from discrimination and marginalization $[18,19]$. Additionally, there are "an increasing number of countries liberalising their regulations on [sex] assignment (and reassignment) of legal sex [20]." In response to this liberalisation movement and in order to promote inclusion and equality, some common social practices have changed. More specifically, social practices that used to be based on the male/female gender binary have expanded their scope to accommodate those whose gender identity extends beyond the binary. A good example of this change is washroom accessibility, where the idea is that transgender people should have the right to access a washroom that accords with their identified gender $[1,2]$. While this is still a growing phenomenon in North America, it is becoming more common in the United Kingdom to not have gendered washrooms at all. ${ }^{3}$ Additionally, and while there is still much work to be done, some healthcare organizations are starting to explicitly inform potential patients that they are an inclusive and welcoming space for the LGBTQ community [21,22].

\section{Involving Trans Persons in Sport: A Brief Overview of Cases and Controversies}

Although some organizations and social practices now support and accommodate transgender people, one industry that continues to grapple with transgender participation is that of the sports industry. Most sporting events categorize athletes based on the male/female gender binary (e.g., male cycling and female cycling, male swimming and female swimming). This poses a challenge for transgender athletes who want to compete in accordance with their gender identity and how they live the rest of their life. The reason that transgender people are often not automatically allowed to compete in the category that aligns with their gender identity is because of a widespread idea that they may possess an unfair advantage in comparison to their cisgender counterparts. This argument is specifically used to criticize and/or to prevent transgender women from competing in female categories, where the idea is that trans women may have an unfair competitive advantage in comparison to cisgender women athletes. The advantage is supposedly based on the effects that may result from a cisgender male's androgen levels (i.e., testosterone), where increased testosterone is thought to contribute to increased strength and speed. As noted in their evaluation of gender segregation in athletics, Foddy and Savulescu say that "[i]t is entirely because of this difference [in having higher levels of androgens] that we consider it unfair to expect women to compete with men in athletic sports." [23] (p. 1184). So, if a trans woman has the biological characteristics of a cisgender male, then the idea is that they will possess athletic advantages that a cisgender woman is unable to naturally attain, thereby making their participation unfair.

The argument that trans women may possess an unfair advantage is seen as problematic by the sports industry because sports are typically guided by a principle called the 'skill thesis' which I have discussed before [3]. The skill thesis is the idea that athletes ought to be rewarded based on skill; the most skillful athlete should be the person who wins [3] (p. 233), [24] (p. 13). The skill thesis is not based on motor skills in particular, but rather the skill(s) that may result from a person having physiological strength, speed, and power, which may be influenced by testosterone levels. ${ }^{4}$ In order for the skill thesis to be realized, athletes need to start from an equal playing field; this requires

\footnotetext{
LGBTQ is the acronym that is used to describe the lesbian, gay, bi-sexual, transgender, and queer community. Thanks to Dr. Emily Ryall for informing me of this more common practice in the United Kingdom.

Thanks to Dr. Emily Ryall for highlighting this distinction for my consideration.
} 
that advantageous external influences (e.g., equipment) and internal influences (e.g., steroid use) are mitigated and monitored. It is widely thought that trans women possess excessively high levels of testosterone in a way that upsets the skill thesis.

While the focus of this paper is on transgender women, it is also the case that some intersex people have encountered similar criticisms to trans women because of the idea that they also possess high testosterone levels and have an unfair advantage. The term 'intersex' is used to classify people who are "born with reproductive systems, chromosomes and/or hormones that are not easily characterized as male or female. This might include a woman with XY chromosomes or a man with ovaries instead of testes [25]." It is important to highlight that transgender women and intersex persons are importantly distinct; "transgender persons are typically born with male/female anatomy but feel as though they are in the wrong body [26] (p. 99)", whereas intersex persons do not necessarily feel as though they are in the wrong body, even though their "phenotype or genotype is atypical with respect to sex markers [26] (p. 99)." The only commonality that may exist amongst transgender and intersex athletes (that is relevant for this paper) is that they are both criticized for having an unfair advantage due to high testosterone levels. Because of this same criticism, I consider examples involving both transgender and intersex athletes below. Ultimately, however, the crux of this paper is focused on transgender women athletes who arguably encounter greater criticisms because of their cisgender male anatomy and changed gender identity.

There have been a number of cases discussed in the media that consider whether transgender women and/or intersex athletes should be allowed to compete in female categories-I will discuss a sample these of cases below.

One of the first controversial cases involving a transgender woman athlete occurred in 1976, involving a professional tennis player named Renee Richards. Richards was scheduled to compete in the female category in tennis, and she was asked to take a sex test. Upon refusing to take the test, Richards was banned from competing [27] (p. 235). She subsequently brought her case to the US Supreme Court who agreed that the sex test requirement was 'grossly unfair, discriminatory and inequitable' [3] (p. 232), [27] (p. 235). Although Richards was permitted to compete in female categories after this ruling, 25 women withdrew from a future tournament because of the belief that Richards retained unfair benefits and muscular advantages of a cisgender male [3] (p. 232), [27] (p. 236).

An additional case which I have described previously [3], is that of mixed martial artist (MMA) Fallon Fox, who was also criticized for having an unfair advantage over her competitors because of her testosterone levels. Fox is a transgender woman and was criticized for competing in the female division because of her differing sex assignment. In 2011 (shortly after Fox's controversial case), the International Association of Athletics Federation (IAAF) developed new regulations for determining athletes' eligibility to compete in female categories. The new regulations required athletes to have testosterone levels of less than $10 \mathrm{nmol} / \mathrm{L}$ at least twelve months before competing [28].

A more recent case involving a transgender woman is that of Laurel Hubbard. Hubbard is a weightlifter and a transgender woman from New Zealand who competed in the female weightlifting category. In 2017, Hubbard won an international weightlifting title in the over-90-kilogram division. Although Hubbard had "a year's worth of blood tests showing ... no more testosterone running through her veins than any of the other female weightlifters competing in the Australian International" [29], the idea that she had an unfair advantage due to her testosterone levels remained present.

Another case where a female athlete was criticized for her testosterone levels is that of intersex athlete Dutee Chand. Chand is a sprinter from India who was criticized for having high testosterone levels after winning gold in the 200-m sprint and the 400-m relay race at the 2014 Asian Junior Athletics Championships. In order to determine her gender, Chand was subjected to a blood test, in addition to "a chromosome analysis, an M.R.I. and a gynecological exam that she found mortifying [30]." She was banned from competing in female categories and advised to take hormone-suppressing drugs or have surgery in order to mitigate her testosterone levels. In response, Chand appealed to the Court of Arbitration for Sport (CAS) in 2015 "questioning why she should be forced to have surgery if her 
condition was natural and she was not ill [31]." Among a number of arguments, Chand claimed that "there was no scientific support for the performance-enhancing effect of high levels of endogenous testosterone [20]."

As a result of Chand's appeal, the CAS questioned whether and/or to what extent an athletic advantage may be possessed by athletes who have naturally high levels of testosterone. In light of this question, the CAS suspended the IAAF's hyperandrogenism regulation and gave them two years to offer more scientific evidence demonstrating the link between "enhanced testosterone levels and improved athletic performance [31]." If no scientific evidence is produced, then the hyperandrogenism regulation would be void. In support of their decision, the CAS said that "[a]lthough athletics events are divided into discrete male and female categories, sex in humans is not simply binary [31]." Moreover, they argued that "[s]ince there are separate categories of male and female competition, it is necessary for the I.A.A.F. to formulate a basis for the division of athletes into male and female categories for the benefit of the broad class of female athletes. The basis chosen should be necessary, reasonable and proportionate to the legitimate objective being pursued [31]." Finally, the CAS found Chand to have established that:

"[I]t is prima facie discriminatory to require female athletes to undergo testing for levels of endogenous testosterone when male athletes do not. In addition, it is not in dispute that the Hyperandrogenism Regulations place restrictions on the eligibility of certain female athletes to compete on the basis of a natural physical characteristic (namely the amount of testosterone that their bodies produce naturally) and are therefore prima facie discriminatory on that basis too [32]."

In alignment with the CAS, the International Olympic Committee (IOC) stopped regulating women's natural testosterone levels until the IAAF case concluded. The IAAF did not produce sufficient evidence about potential advantages assumed by hyperandrogenous women as a result of increased testosterone levels by the 2017 deadline.

In 2018, however, the IAAF published new criteria for athletes competing in female categories [32]. The new criteria apply to five track events and require all female athletes with 'differences of sexual development' (DSDs) to reduce their testosterone levels to below $5 \mathrm{nmol} / \mathrm{L}$. The change of acceptable testosterone level was based on research conducted by Dr. Bermon of the IAAF Medical and Science Department, who said that there is a "performance advantage in female athletes with DSD over the track distances covered by this rule [32]." Although this is the present standard, the research produced by Dr. Bermon was recently contested by Pielke et al., who suggest that the scientific integrity of the research is flawed [33]. So, it appears that we may be back to a place of uncertainty in terms of knowing whether and/or how much testosterone may lead to significant advantages.

The final and most recent case that I will discuss here is that of Caster Semenya. Semenya, who is believed to be intersex, was the 800-metre track and field winner at the 2009 world championships, 2012 Olympics, and 2016 Olympics. After her victory in 2009, she was criticized for being "too masculine", barred from the competition, and subjected to sex tests. According to available reports, Semenya has a condition called hyperandrogenism, which is when a person's body produces a large amount of testosterone [34]. Consequently, Semenya was seen as having an unfair advantage in comparison to other athletes in the female category.

As mentioned above, the IAAF published new criteria for athletes competing in female categories in response to Chand's case. The criteria were supposed to come into effect in November 2018, but Semenya challenged the rules to the CAS [34]. In response, the CAS granted a panel of three judges the responsibility of performing an evaluation and reaching a verdict about Semenya's appeal. After months of deliberation, the verdict was finally announced, requiring Semenya and others with high testosterone levels to lower them [35]. While some agree with the CAS verdict, many athletes, fans, and organizations have spoken out against the ruling. For instance, Canada's sport and science minister, Kirsty Duncan, reportedly said "I do not think a sport organization should be deciding who is a woman 
or what makes a woman. I don't think any sport organization should be telling an athlete to alter their body chemistry. We ask that our athletes do not take drugs. Now an athlete is being told her alter her natural body chemistry [35]." While this ruling was initially motivated by and challenged by intersex athletes, the outcome of requiring athletes to have certain testosterone levels will plausibly influence transgender women as well.

\section{Trans Women in Sport: Discussing a Previous Argument}

In a 2017 article, I discussed the skill thesis and the topic of transgender women competing in female categories [3]. The purpose of the article was to respond to the question of whether trans women should be allowed to compete in female categories. I will briefly describe my previous argument here and then propose a novel expansion of it in the section below (Section 4).

I commenced my 2017 article "Transgender Women in Sport" by suggesting that while the idea that transgender women possess high testosterone levels is a frequently used justification to preclude them from competing in female categories, the science behind this argument is vague. ${ }^{5}$ In fact, it may be the case that " the presence of high testosterone does not guarantee an increased level of performance. Rather, the way that one's body responds to testosterone is relevant (Schultz 2011) [3] (p. 233)."' I subsequently argue that if this is correct (i.e., the idea that high testosterone does not guarantee an increased performance level in and of itself) ${ }^{6}$ then it seems that the real argument against trans women competing in female categories is "based on the assumption that they have a higher level of effective testosterone in comparison to their cisgender competitors [3] (p. 233)." I use the term effective testosterone to refer to "the testosterone that can be effectively used by one's body in order to benefit or enhance one's performance [3] (p. 234)." And if it is the case that trans women have unfairly high levels of effective testosterone, then they may be unfairly advantaged from the perspective of the skill thesis.

After considering the possibility that trans women may have high effective testosterone levels such that skill thesis is undermined, I argue that the skill thesis is, in fact, already undermined because of the natural genetic lottery. The genetic lottery makes it such that some people are going to be advantaged in ways that others are not, making it impossible to commence a sporting event from a place of even proximate equality amongst athletes; a male/female gender binary in sports does not allow the skill thesis to properly exist $[3,23]$. I draw on a couple of examples to illustrate this point, such as the case of Michael Phelps, whose genetic attributes provide him with many advantages that his competitors probably lack (e.g., size 14 feet, the fact that he is double jointed, his large 'wingspan') $[3,23,36]$. So, if genetic advantages already exist in sport even though the skill thesis exists, then there may be a reason to question the legitimacy of the argument against trans women competing in female categories. ${ }^{7}$

After highlighting that genetically advantageous attributes already exist in sport, I argue that we can proceed in either one of two ways when it comes to considering if transgender women should be permitted to compete in female categories: (1) we can accept that the skill thesis is unrealistic and allow trans women to compete in female categories even if they have an increased level of effective testosterone or (2) we can argue that the skill thesis ought to be maintained and that all potentially unfair genetic advantages need to be mitigated in male and female categories for both cisgender and transgender athletes. While I recognize that skill thesis/striving for equality amongst athletes may be problematic (as also mentioned by Gleaves and Lehrbach [37] (pp. 314, 315)), I ultimately decide to explore the second option (i.e., mitigating potentially unfair advantages) given the prevalence of

\footnotetext{
Furthermore, it appears that the science is still vague if Dr. Bermon's narrow research produced flawed results. The idea that trans women have a high level of effective testosterone is still unproven.

In my former article, I discuss that there may be a distinction to be made between different kinds of genetic features. When considering transgender women in sport, it may be relevant to consider whether cisgender women would be capable of achieving the same kinds of advantages that trans women possess. If no, then it may be the case that only trans women who undergo certain hormonal interventions should be permitted to compete in female categories. While recognizing that this may be a possibility, I focus the article on all trans women given the broad range of persons who may identify as a woman irrespective of interventions [3].
} 
the skill thesis. I specifically focus on mitigating effective testosterone levels since that is the primary attribute that seems to preclude trans women from competing in accordance with their gender identity.

In concluding the 2017 paper, I argue that one way to maintain the skill thesis and to mitigate effective testosterone levels is to implement a handicap system that focuses on effective testosterone levels. ${ }^{8}$ Handicap systems are already used in some sports (e.g., golf) to "assist players to play on somewhat equal terms so that the results accurately reflect players' skill [3] (p. 238)." With this goal in mind, I argue that a handicap system may be the most helpful way to allow transgender women to compete in female categories by recognizing and accounting for the way that effective testosterone levels may undermine the skill thesis. Ultimately, I propose that the effective testosterone levels of transgender and cisgender athletes ought to be calculated and compared to one another in order to determine if anyone is unfairly advantaged. If an athlete has an excessive amount of effective testosterone then I argue that the corresponding advantage would need to be considered when determining their ranking (e.g., whether they deserve to be granted first place or, in fact, whether their effective testosterone level provided them with an unfair advantage such that a first place finish does not accord with the skill thesis). By using a handicap system, I argue that the appropriate winner can be determined while at the same time allowing trans women to fairly compete in female categories.

\section{Next Steps: A Potential Re-Consideration of the Gender Divide in Sport}

The question of whether transgender women athletes should be permitted to compete in female categories has not been resolved. In fact, the CAS is currently exploring the issue in order to determine an ethically defensible and scientifically valid solution [38]. Perhaps this provides some justification to revisit my proposed handicap system mentioned above. The other option previously put forward (which may also be worth reconsidering) is to abandon the skill thesis and allow transgender athletes to compete in accordance with their gender identity; this option may be justified by the fact that genetic advantages already exist in sport. However, it also seems plausible that a third option may be worth considering, and this option may serve as a natural extension to my previous proposal.

As mentioned above, my previous article concluded that a handicap system ought to be implemented in order to maintain the skill thesis and allow trans women to participate in female categories. This conclusion begs the question, however, as to whether a gender divide is necessary to maintain at all, or whether a larger change may be warranted. More specifically, it seems that my previous proposal leads to the suggestion that instead of trying to maintain the skill thesis by mitigating unfair advantages within sex specific categories, it may make more sense to simply abolish the categories themselves.

There are a couple of theorists who have already considered the relevance of maintaining sex specific categories in sport. In 2011, Foddy and Savalescu considered whether segregating sports based on gender performance is defensible, where they focus on intersex athletes and Semenya's case [23]. The authors highlight that gender is not binary and they briefly consider the possibility and challenges of using testosterone levels to categorize athletes (similar to my previous proposal) [23] (p. 1187). Ultimately, they conclude that there is no justification for excluding intersex athletes from current categories because of genetic variants [23] (p. 1188).

Another theorist who has considered sex specific categories in sport is Torbjörn Tännsjö [4]. Tännsjö argues that sex specific categories ought to be abolished. Rather than being primarily motivated by the skill thesis, however, Tännsjö's argument is based on the idea that sexual discrimination is morally objectionable. More specifically, he argues that if sexual discrimination (namely, the idea that women are treated differently and as less capable than men) is morally objectionable in most contexts, then it should also be deemed problematic in the sports industry [4] (p. 347). In order to truly promote

8 My argument in this paper is based on the assumption that effective testosterone levels are, in fact, relevant to determining whether a transgender woman is unfairly advantaged. 
gender equality and to achieve the primary purpose of sporting events (namely, to determine the best athlete), Tännsjö says that a gender binary system should not exist. All athletes should compete against one another and the best athlete should have the opportunity to win, regardless of whether this is a cisgender or transgender male or female. ${ }^{9}$

There exist two potential challenges in response to Tännsjö's argument. First, one may respond by arguing that sex specific categories in sport are not an unjust form of sexual discrimination in and of themselves and only unjust discriminatory categories are problematic. For instance, if evidence does exist which suggests that male and female athletes ought to be categorized separately in order to maintain fairness and/or if female athletes want to be categorized separately, then perhaps sex specific categories may be justifiable. Tännsjö's argument does not lend any possibility to these potential responses because his view is based on the assumption that the gender binary in sports is a form of unjust sexual discrimination.

The second argument that could be used to oppose Tännsjö's proposal has to do with ensuring that cisgender women are provided with the opportunity to compete in competitive sports in general; proponents of this argument would support the maintenance of sex specific categories (based on sex assignments). Originally, competitive sporting events, such as the Olympics, only permitted male athletes to compete. It was not until the 1900 Paris Summer Games that sex specific events were established and women were allowed to participate [39]. The fact that female categories in sport were established after male categories, in addition to the challenges that many cisgender women continue to experience when it comes to being treated as equal members of society, has led some scholars to maintain a protective lens in support of specific female categories for cisgender women athletes. The argument goes as follows: Allowing transgender women (i.e., people with a male sex assignment) to compete against cisgender women in sport may result in more transgender women being successful because of their male physiology (e.g., increased testosterone, height, weight, foot size, arm length, etc.), consequently resulting in less representation from cisgender women athletes. This consequence would be detrimental to the progress that women have made in in the sports industry. Thus, the argument ultimately suggests that sex specific categories ought to be maintained, and that transgender women should not be permitted to compete in female categories in order to (1) maintain the skill thesis and (2) ensure equal representation in sport for cisgender women athletes.

In response to this argument regarding cisgender representation, it may be worth noting that there is still no conclusive evidence to support the claim that transgender women are higher performers than their cisgender counterparts, and evidence is important when it comes to developing rules [40] (p. 14). As discussed in their systematic review about sport and transgender people, Jones et al. say that there is "no direct or consistent research suggesting transgender female individuals (or male individuals) have an athletic advantage at any stage of their transition (e.g., cross-sex hormones, gender-confirming-surgery) [41]." Melanie Newbould makes a similar claim, saying that "the hypothesis that women with testes have an advantage has not been subjected to close scientific scrutiny [5]." Furthermore, Newbould says that even if high testosterone levels provide athletes with some helpful benefits, "athletic ability depends on a much wider range of factors such as natural talent for the sport, genetic composition, personal interest and motivation, appropriate training, nutrition and so on [5] (p. 257)." One may respond to Jones et al. and Newbould, however, by saying that the majority of world sport records are held by cisgender men, thereby suggesting that that there appears to be some advantageous differences that are a consequence of cisgender male physiology [42]. Relatedly, one may argue that transgender women who have not undergone any physiological transition measures may possess certain advantages in comparison to those who have pursued hormonal interventions. Although there may be differences amongst some cisgender men and women making it such that some transgender women may possess certain advantages, the lack of conclusive evidence makes it such

9 Note: Tännsjö does not focus on transgender men and women but rather cisgender women in general. 
that it may be premature to preclude an entire group of people (i.e., transgender individuals) from competing in accordance with their gender identity at this point in time.

Since there currently exists no strong conclusive evidence in support of the unfair advantages possessed by transgender women (who either have or have not undergone a transition-related surgery), it may be unfair to prevent them from competing in female categories. However, even if evidence eventually shows that some transgender women have an unfair advantage, then this still does not necessarily mean that preventing them from competing in female categories is the best option to pursue if we want to maintain the skill thesis. As mentioned above, the skill thesis is a prevalent guiding principle in sport, where the goal is to ensure that the most skillful athlete can win in the absence of unfair advantages $[3,40]$ (p. 10). The skill thesis does not suggest that that sex specific categories should be the focus of enabling athletes to start from an equal playing field. So, instead of categorizing and separating athletes based on sex, perhaps athletes should instead be categorized based on something else. This is precisely the idea that Newbould considers when contemplating options for transgender athletes who have and have not undergone surgical interventions. Newbould proposes that it may make sense to categorize people based on their testosterone level rather than sex assignment (e.g., high testosterone and low testosterone groupings) [5] (p. 258). This is similar to my 2017 proposal regarding effective testosterone and the handicap system.

There are multiple problems with Newbould's suggestion and my previous proposal. One of these problems is that effective testosterone levels cannot be measured at the present time. And if it is the case that how one's body uses testosterone (i.e., effective testosterone) is the primary indicator of potentially unfair advantages, then the inability to measure it is problematic. Also, and most importantly, it is still unclear whether testosterone is, in fact, the primary factor that poses possible advantages for transgender women. Because of this uncertainty, it seems moot to focus on testosterone levels when it comes to considering advantages within sex specific sports categories and/or as the primary factor for new categories.

Instead of pursuing my previous proposal or Newbould's suggestion, perhaps considering factors other than solely testosterone would be more apt when it comes to contemplating what fair categories in sport might look like. So, rather than categorizing people based on their sex assignment, a new system might categorize athletes based on potentially more relevant factors, where the factors could be sport-dependent (e.g., high jump might primarily take into account athletes' heights and testosterone levels, swimming might primarily take into account athletes' foot sizes, heights, arm spans, etc.). According to this proposal, the development of and any changes that are made to categorization criteria would be based on characteristics that are most relevant to specific sports as determined by pertinent stakeholders (e.g., sports organizations, athletes, etc.), thereby allowing sports organizations to separate athletes with certain types of genetic advantages into categories of their own, if possible. If this kind of categorization system were to occur, then it might be the case that some sports would end up separating persons based on their sex assignment, but their sex assignment alone would not determine the categories. So, if some athletes just so happen to compete against others who have the same sex assignment, then this would be dependent on factors that extend beyond their sex.

The proposal to eliminate sex specific categories in favour of categorizing athletes based on other potentially more relevant criteria seeks to maintain the skill thesis, making it a natural extension to my previous proposal (i.e., the handicap system) [3]. It also seeks to eliminate potentially discriminatory and/or unjustified/arbitrary classifications based on sex assignment alone. The difference between this new idea of categorizing people based on factors other than sex and the handicap system is that my former proposal still maintained sex specific categories and tried to mitigate unfair advantages within the gender binary system; the new proposal does not. Furthermore, my motivation for reconsidering the defensibility of male/female categories in sport is different from Tännsjö's. My primary motive is based on maintaining the skill thesis given its prevalence in the sports world, and the skill thesis cannot be achieved with sex specific categories irrespective of whether evidence develops that deems transgender women to have an unfair advantage. As a consequence of reconsidering the gender divide, 
a more inclusive athletic environment for transgender athletes will be established. At the present time, transgender women athletes are frequently shunned from competitive sport environments at least in part because sex specific categories exist and the idea that they have an unfair advantage is widespread. One way to address this problem is to reconsider the gender divide and eliminate sex specific categories in favour of a different categorization system. The option to abolish the gender divide would also influence athletic events to be more welcoming and accepting of non-binary athletes since one's sex assignment and gender identity would be irrelevant to the categories.

One potential problem with this new proposal is that if cisgender male athletes just so happen to have physiological advantages that enable them to compete at a different (i.e., higher) performance level than cisgender women, then cisgender women may be excluded from competitive sports. This is a significant concern from an equality standpoint, especially since women often encounter disadvantages in society and this performance variance could potentially and negatively influence their status in other domains [43]. In one respect, however, if every competitive sport has multiple categories based on relevant factors then there will plausibly be a smaller likelihood that cisgender women will be completely excluded. For instance, if all competitive swimming events have categories for people with wingspan X (i.e., a large span) and wingspan $Y$ (i.e. a shorter span), in addition to other factors, then cisgender women may be more likely to be included if it just so happens that most cisgender male competitors have wingspan $X+$ other relevant factors and most cisgender women have wingspan $X$. If this turns out to not be the case, however, then perhaps sports organizations would want to develop categories for certain sports that will take into account cisgender women athletes for representation and inclusivity purposes. At the same time, it would be important to ensure that any categories developed are not seen as 'lesser than' the others, which may be hard to achieve. Ultimately, the existence of this potential problem does not in and of itself justify the maintenance of our current sport categories, but it does encourage us to ensure that we thoughtfully approach any new recommendations.

\section{Conclusions}

Most sporting events are currently based on the male/female gender binary. This sex specific categorization is unhelpful, however, when it comes to managing transgender women athletes who are criticized for having an unfair advantage over their cisgender counterparts. One of the primary reasons that transgender women are criticized is because of the idea that they may have high testosterone levels, resulting in increased levels of performance. Cases such as Renee Richard's, Caster Semenya's, Fallon Fox's, Laurel Hubbard's, and Dutee Chand's have brought this issue to the forefront of the sports world. Although the topic of including transgender women in sport is being debated, there currently exists no conclusive evidence to support the argument that some trans women may possess unfair advantages and/or that these advantages are somehow different than other advantages that may already exist in sport.

Current efforts to manage the debate are primarily based on the maintenance of sex specific categories in sport, which is guided by the skill thesis. In a previous article, however, I showed that the skill thesis cannot be achieved because of the natural genetic lottery, which offers potentially unfair advantages to certain athletes. If the skill thesis continues to be a guiding principle in sport, then it may make sense to not only mitigate potentially unfair advantages in sex specific categories (which is what I previously suggested) but also to abolish the gender divide. Rather than separating athletes based on their sex assignment to try to achieve the skill thesis, perhaps alternative factors ought to be considered. Newbould proposes that factors such as testosterone levels ought to be the basis from which athletes are categorized. Similarly, I suggest that factors such as testosterone or other relevant factors (depending on the sport) ought to be taken into account. Reconsidering the legitimacy of the current gender divide in sport may allow the skill thesis to be better attained and lead to a more inclusive environment for all athletes, regardless of their gender identity and sex assignment.

Funding: This research received no external funding. 
Acknowledgments: I would like to thank Dr. Christopher Grafos for his thoughtful feedback on earlier versions of this manuscript. Also, many thanks to Dr. Emily Ryall for her recommendations and support on the development of this paper.

Conflicts of Interest: The author declares no conflict of interest.

\section{References}

1. Goodyear, S. Transgender Bathroom Debate Has Students Wondering What the Big Deal Is. CBC News, 24 May 2016. Available online: https:/www.cbc.ca/news/canada/transgender-school-policies-bathroomsstudent-voices-1.3589717 (accessed on 19 April 2019).

2. U.S. Department of Labor-Occupational Safety and Health Administration. A Guide to Restroom Access for Transgender Workers. 2015. Available online: https://www.dol.gov/asp/policy-development/ TransgenderBathroomAccessBestPractices.pdf (accessed on 19 April 2019).

3. Bianchi, A. Transgender Woen in Sport. J. Philos. Sport 2017, 44, 229-242. [CrossRef]

4. Tännsjö, T. Against Sexual Discrimination in Sports. In Values in Sport: Elitism, Nationalism, Gender Equality and the Scientific Manufacturing of Winners, 1st ed.; Tamburrini, C., Tännsjö, T., Eds.; Taylor \& Francis: London, UK, 2000; pp. 101-115.

5. Newbould, M.J. What do we do about women athletes with testes? J. Med. Ethics 2016, 42, 256-259. [CrossRef] [PubMed]

6. Trans/Transgender. The 519 Glossary of Terms. Available online: http://www.the519.org/education-training/ glossary (accessed on 19 April 2019).

7. Ryall, E. Philosophy of Sport: Key Questions; Bloomsbury: London, UK, 2016.

8. National Center for Transgender Equality. How Does Someone Know That They Are Transgender? 2016. Available online: https://ransequality.org/issues/resources/frequently-asked-questions-about-transgenderpeople (accessed on 19 April 2019).

9. Increase in Transgender Kids. Castanet.net. 2012. Available online: http://www.castanet.net/news/World/ 71255/Increase-in-transgender-kids (accessed on 19 April 2019).

10. Associated Press. Sex Change Treatment for Kids on the Rise. CBS News. 20 February 2012. Available online: http://www.cbsnews.com/news/sex-change-treatment-for-kids-on-the-rise/ (accessed on 19 April 2019).

11. Weiler, N. Transgender Kids: 'Exploding' Number of Children, Parents Seek Clinical Help. Mercury News, 5 June 2015. Available online: http://www.mercurynews.com/2015/06/05/transgender-kids-explodingnumber-of-children-parents-seek-clinical-help/ (accessed on 19 April 2019).

12. Gender Expression. Available online: http://www.the519.org/education-training/glossary (accessed on 28 January 2019).

13. National Center for Transgender Equality. Housing \& Homelessness. Available online: https://ransequality. org/issues/housing-homelessness (accessed on 19 April 2019).

14. National Center for Transgender Equality. Health \& HIV. Available online: https://transequality.org/issues/ health-hiv (accessed on 19 April 2019).

15. Bauer, G.; Boyce, M.; Coleman, T.; Kaay, M.; Scanlon, K.; Travers, R. Who Are Trans People in Ontario? Report No:1(1); Trans PULSE E-Bulletin: Toronto, ON, Canada, 2010; Available online: http://transpulseproject.ca/ research/who-are-trans-people-in-ontario/ (accessed on 19 April 2019).

16. NPR; The Robert Wood Johnson Foundation; Harvard T.H. Chan School of Public Health. Discrimination in America: Experiences and Views of LGBTQ Americans. Available online: https:/www.npr.org/documents/2017/ nov/npr-discrimination-lgbtq-final.pdf (accessed on 19 April 2019).

17. Powell, A. The Problems with LGBTQ Health Care. The Harvard Gazette. 26 March 2018. Available online: https://news.harvard.edu/gazette/story/2018/03/health-care-providers-need-better-understandingof-lgbtq-patients-harvard-forum-says/ (accessed on 19 April 2019).

18. United Nations. Ban Calls for Efforts to Secure Equal Rights for LGBT Community; United Nations: New York, NY, USA, 2016. Available online: https://www.un.org/sustainabledevelopment/blog/2016/09/ban-calls-forefforts-to-secure-equal-rights-for-lgbt-community/ (accessed on 18 April 2019).

19. Ontario Human Rights Commission. Gender Identity and Gender Expression (Brochure). Available online: http://www.ohrc.on.ca/en/gender-identity-and-gender-expression-brochure. (accessed on 19 April 2019). 
20. Ljungqvist, A. Sex segregation and sport. Br. J. Sports Med. 2018, 52, 1481-1482. [CrossRef] [PubMed]

21. Rainbow Health Ontario. Service Provider Directory. Available online: https://www.rainbowhealthontario. ca/service-directory/ (accessed on 19 April 2019).

22. Roussy, K. Hospital Staff in Toronto Learn the Dos and Don'ts of LGBTQ Lingo. CBC News, 1 July 2016. Available online: https://www.cbc.ca/news/health/transgender-hospital-toronto-lgbtq-canada-1.3655169 (accessed on 19 April 2019).

23. Foddy, B.; Savulescu, J. Time to re-evaluate gender segregation in athletics? Br. J. Sports Med. 2011, 45, 1184-1188. [CrossRef] [PubMed]

24. Simon, R. Deserving to Be Lucky: Reflections on the Role of Luck and Desert in Sports. J. Philos. Sport 2007, 34, 13-25. [CrossRef]

25. Intersex. The 519 Glossary of Terms. Available online: http://www.the519.org/education-training/glossary (accessed on 19 April 2019).

26. Dea, S. Beyond the Binary: Thinking About Sex and Gender; Broadview Press: Peterborough, ON, Canada, 2016.

27. Schultz, J. Caster Semenya and the "Question of Too": Sex Testing in Elite Women's Sport and the Issue of Advantage. Quest 2011, 63, 228-243. [CrossRef]

28. Karkazis, K.; Carpenter, M. Impossible Choices: The Inherent Harms of Regulating Women's Testosterone in Sport. Bioethical Inq. 2018, 15, 579-587. [CrossRef] [PubMed]

29. Payne, M. Transgender Woman Wins International Weightlifting Title amid Controversy Over Fairness. Washington Post, 22 March 2017. Available online: https://www.washingtonpost.com/news/early-lead/wp/ 2017/03/22/transgender-woman-wins-international-weightlifting-title-amid-controversy-over-fairness/ ?noredirect=on (accessed on 19 April 2019).

30. Padawer, R. The Humiliating Practice of Sex-Testing Female Athletes. New York Times, 28 June 2016. Available online: https://www.nytimes.com/2016/07/03/magazine/the-humiliating-practice-of-sex-testingfemale-athletes.html (accessed on 19 April 2019).

31. Branch, J. Dutee Chand, Female Sprinter with High Testosterone Level, Wins Right to Compete. New York Times, 27 July 2015. Available online: https://www.nytimes.com/2015/07/28/sports/international/dutee-chandfemale-sprinter-with-high-male-hormone-level-wins-right-to-compete.html (accessed on 19 April 2019).

32. IAAF Introduces New Eligibility Regulations for Female Classification. Available online: https://www.iaaf. org/news/press-release/eligibility-regulations-for-female-classifica (accessed on 19 April 2019).

33. Pielke, R., Jr.; Tucker, R.; Boye, E. Scientific integrity and the IAAF testosterone regulations. Int. Sports Law J. 2019, 1-9. [CrossRef]

34. Campigotto, J. The Caster Semenya Case Could Shape the Future of Women's Sports. CBC News. 30 April 2019. Available online: https://www.cbc.ca/sports/olympics/trackandfield/caster-semenya-explainer-1.5116897 (accessed on 8 May 2019).

35. Dunbar, G. Caster Semenya Loses Appeal Against IAAF Testosterone Rules. CBC News, 1 May 2019. Available online: https://www.cbc.ca/sports/olympics/trackandfield/caster-semenya-appeal-1.5117936 (accessed on 8 May 2019).

36. Hadhazy, A. What Makes Michael Phelps So Good? Scientific American, 18 August 2008. Available online: http://www.scientificamerican.com/article/what-makesmichael-phelps-so-good/ (accessed on 19 April 2019).

37. Gleaves, J.; Lehrbach, T. Beyond fairness: The ethics of inclusion for transgender and intersex athletes. J. Philos. Sport 2016, 43, 311-326. [CrossRef]

38. Koshie, N. Indian Express. 6 April 2019. Available online: https://indianexpress.com/article/sports/sportothers/cass-verdict-on-caster-semenya-testosterone-case-5661681/ (accessed on 19 April 2019).

39. Reeser, J.C. Gender identity and sport: Is the playing field level? Rev. Br. J. Sports Med. 2005, 39, 695-699. [CrossRef] [PubMed]

40. Coggon, J.; Hammond, N.; Holm, S. Transsexuals in Sport-Fairness and Freedom, Regulation and Law. Sportsethics Philos. 2008, 2, 4-17. [CrossRef]

41. Jones, B.A.; Arcelus, J.; Bouman, W.P.; Haycraft, E. Sport and Transgender People: A Systematic Review of the Literature Relating to Sport Participation and Competitive Sport Policies. Sports Med. 2017, 47, 701-716. [CrossRef] [PubMed] 
42. IAAF. Olympic Games Records. Available online: https://www.iaaf.org/records/by-category/olympic-gamesrecords (accessed on 19 April 2019).

43. English, J. Sex Equality in Sports. Philos. Public Aff. 1978, 7, 269-277.

(c)

(C) 2019 by the author. Licensee MDPI, Basel, Switzerland. This article is an open access article distributed under the terms and conditions of the Creative Commons Attribution (CC BY) license (http://creativecommons.org/licenses/by/4.0/). 